\title{
Cost-Effectiveness of Dimethyl Fumarate Compared to Teriflunomide for Relapsing Remitting Multiple Sclerosis Patients in Italy
}

\author{
Lorenzo Giovanni Mantovani ${ }^{1}$, Paolo Angelo Cortesi ${ }^{1}$, Alessandra Cardillo ${ }^{2}$, \\ Laura Santoni ${ }^{2}$, Luca Prosperini ${ }^{3}$ \\ Research Centre on Public Health (CESP), University of Milan - Bicocca, Monza, Italy \\ Biogen Italia, Milan, Italy \\ 3 Department of Neurosciences, S. Camillo-Forlanini Hospital, Rome, Italy
}

\begin{abstract}
BACKGROUND: The objective of this economic analysis was to compare the cost-effectiveness of dimethyl fumarate vs teriflunomide for the treatment of adult patients with relapsing-remitting multiple sclerosis (RRMS) in the Italian setting. Additionally, the cost-effectiveness analysis was used to predict some patient-relevant outcomes such as burden of relapses and survival with disability over time.

METHODS: A Markov model was used to conduct the cost-effectiveness analysis. The model measured health outcomes and costs of RRMS patients treated with either dimethyl fumarate or teriflunomide. Data from a published mixed treatment comparison were used for efficacy and safety input. Local economic data were used to calculate costs. A supplementary analysis was carried out to assess ICER variability over time from the Italian National Healthcare Service (NHS) and societal perspectives. Further analyses were conducted to compare clinical effectiveness of the alternatives over time, in terms of incidence of relapses, proportion of patients with EDSS (Expanded Disability Status Scale) score $\leq 3$ and EDSS score $\geq 6$. RESULTS: In the base-case analysis (lifetime horizon; societal perspective) dimethyl fumarate was dominant over teriflunomide (6.526 vs 5.953 QALYs - quality-adjusted life-years; $€ 1.01 \mathrm{M}$ vs $€ 1.03 \mathrm{M}$ ). The most relevant cost savings (per-patient) with dimethyl fumarate were related to relapses $(-€ 5,096)$, inpatient care $(-€ 5,767)$, informal care $(-€ 9,603)$, long-term absence/early retirement $(-€ 14,187)$. The additional analysis of ICER by time horizon shows that dimethyl fumarate is cost-effective vs teriflunomide (i.e., ICER $<€ 50,000$ per QALY gained) at already 6 years and at 15 years in societal or NHS perspectives, respectively. Results favoured dimethyl fumarate vs teriflunomide also for: cumulative burden of relapses (-0.23 and -1.37 relapses saved per patient already at 1 year and 10 years, respectively), proportion of patients with mild disability $(+4.0 \%$ at 10 years), proportion of patients with severe disability $(-4.0 \%$ at 10 years).

CONCLUSIONS: Dimethyl fumarate is dominant (societal perspective), or cost-effective (NHS perspective), referring to a threshold of $€ 50,000$ per QALY gained, vs teriflunomide for the first-line treatment of RRMS, in the Italian setting.
\end{abstract}

\section{Keywords}

Dimethyl Fumarate; Teriflunomide; Relapsing-Remitting Multiple Sclerosis; Cost-Effectiveness; Quality-Adjusted Survival

\section{INTRODUCTION}

Multiple Sclerosis (MS) is a demyelinating disease that affects the central nervous system (brain and spinal cord). In 2019, MS prevalence was about 2.8 million subjects worldwide [1], 750 thousand in Europe [2] and 122 thousand in Italy, where every year new 3,400 cases are diagnosed $[2,3]$.

MS onset can occur at any age of life, but is mostly observed in young adults, aged between 20 and 40 years old $[4,5]$. This brings considerable clinical and economic burden on patients, healthcare systems and society [6-8].

In Italy, the annual societal costs of MS amount to about $€ 5$ billion [3]. Studies on the economic impact for society (i.e. evaluating both healthcare and non-healthcare direct and indirect costs) show that the annual costs per patient are in the range of $€ 45$ thousand [3].

Corresponding author Paolo Angelo Cortesi paolo.cortesi@unimib.it Published: 7 February 2022 
Reasonably, the economic burden of MS increases with the severity of the disease and its associated disability, ranging from about $€ 18,000$ for patients with mild disability, up to $€ 84,000$ for the most severe patients [3].

Relapsing-remitting multiple sclerosis (RRMS) is the most common form of MS. About $85 \%$ of patients with MS have a relapsing-remitting form at disease onset [9]. Within 20-25 years, $\sim 60-70 \%$ of RRMS patients enter a second disease phase characterized by continuous, irreversible neurological decline unassociated with relapses (secondary progressive form - SPMS) [9]. The remaining $15 \%$ of patients have a primary progressive form (PPMS) at diagnosis [9].

Several decades ago, the approval and introduction of the first-generation therapies for RRMS (interferon $\beta-1 b$, interferon $\beta$-1a, glatiramer acetate) dramatically changed the natural history of the disease. As a matter of fact, these therapies had and still have an important role in the RRMS therapeutic algorithm, as they can prevent relapses, reduce disease activity, and consequently delay disease progression and disability accumulation (disease-modifying therapies, DMTs). However, despite the unprecedented efficacy in this therapeutic area, it was quite clear to the scientific community that treatment with injectable therapies in RRMS was only partially addressing the unmet medical need of RRMS [10-12], with some clinical issues remaining open. Limited efficacy in managing highly active forms, limited duration of effect, discomfort of patients for injectable therapies driven by tolerability issues, were some of the main drawbacks associated with first-generation therapies. Such limitations pushed scientists to develop new options to manage patients more appropriately during both the initial phases of the disease, and in patients with refractory disease [10-12].

The first-line oral therapies dimethyl fumarate (delayed-release dimethyl fumarate, also known as gastro-resistant dimethyl fumarate, trade name: Tecfidera ${ }^{\circledR}[13,14]$ ) and teriflunomide (trade name: Aubagio ${ }^{\circledR}[15,16]$ ) have been developed to effectively prevent relapses, delay disability progression in RRMS, overcome the typical issues of first-generation therapies, improve patients' quality of life and finally provide physicians with therapeutic options with novel mechanisms of action. While the increase in the number of therapeutic options is certainly a great opportunity for patients and physicians, who can "personalize" treatment, multiple options pose important questions regarding economics, i.e. prescribing cost-effectively. In this paper, we aimed to compare costs and outcomes of delayed-release dimethyl fumarate (hereafter defined as "dimethyl fumarate", for simplicity), vs. teriflunomide in the Italian population, according to the approved indication, for the treatment of adult patients with RRMS. The rationale for choosing dimethyl fumarate and teriflunomide is that it was intended to compare the two first-line oral therapies for the treatment of RRMS.

\section{MATERIALS AND METHODS}

\section{Study design}

This cost-effectiveness analysis was carried out by adapting a Markov model (previously in other cost-effectiveness evaluations in RRMS [17-20]), to the Italian setting. The model was developed to simulate the clinical and economic outcomes of a hypothetical cohort of RRMS patients, that could either receive dimethyl fumarate (240 mg twice a day) or teriflunomide (14 mg daily). More specifically, this model is a cohort-based Markov model in which patients are able to progress through a series of disability health states (measured through the Expanded Disability Status Scale -EDSS- [21]).

At the beginning of the simulation, patients enter the model and are allocated in different EDSS health states, according to their baseline characteristics. During model simulation, patients can experience: i) disease progression (EDSS increase); ii) disease improvement (EDSS decrease); iii) stable disease (unchanged EDSS score). Furthermore, patients can also progress to the SPMS form, where they will progress at a faster rate. Patients transitioning from RRMS to SPMS will also transition from EDSS score " $x$ " (in the RRMS form) to EDSS score " $\mathrm{x}+1$ " (in the SPMS form). After transition to the SPMS form, patients can either progress to a higher EDSS state, or remain in their current state.

In the RRMS form, treatment with dimethyl fumarate and teriflunomide have the effect of modifying the natural disease progression, by reducing disease activity and delaying disability accumulation. Furthermore, it is assumed that: i) treatment with DMTs does not have any effect in preventing transition from RRMS to SPMS and delaying disability progression within the SPMS form; ii) treatment with DMTs is interrupted when patients reach an EDSS score $\geq 7$ or when they switch to the SPMS form (any EDSS level). 
Overall, the model consists of 21 health states: 10 states corresponding to the possible 10 disability levels (i.e. EDSS scores) in the RRMS form; 10 states corresponding to the possible 10 EDSS disability levels in the SPMS form; 1 death health state. A graphical illustration of the Markov model is shown in Figure 1. In the base-case analysis, dimethyl fumarate was evaluated vs. teriflunomide, adopting: i) societal perspective (i.e. including direct and indirect costs); ii) 50-year time horizon (lifetime); iii) 3.5\% discount rate on both outcomes and costs, as recommended by NICE (National Institute for Health and Care Excellence) [22]. One-year cycles were used for this Markov model.

\section{Data source}

\section{Baseline characteristics}

The analysis refers to a hypothetical co-

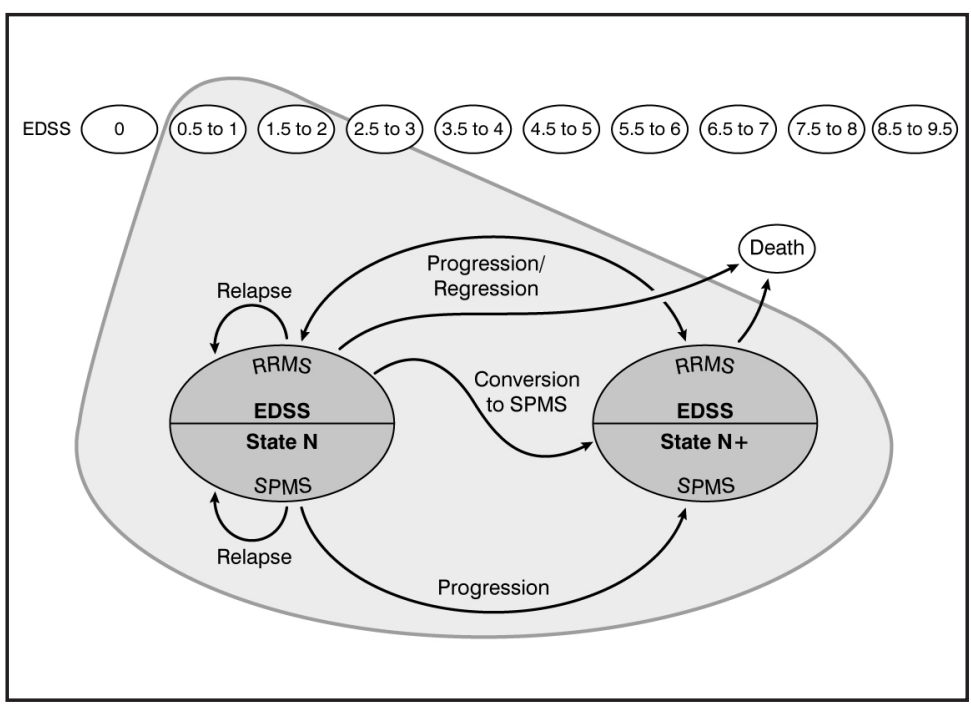

Figure 1. Scheme of the Markov model used for the analysis (adapted from [19]) EDSS = expanded disability status scale; RRMS = relapsing-remitting multiple sclerosis; SPMS $=$ secondary progressive multiple sclerosis

hort of Italian patients affected by RRMS. It is assumed that the analysed patient population would have same baseline characteristics as observed in the clinical trials DEFINE and CONFIRM [23,24]. At baseline, patients have a mean age of 37.8 years, and $28.6 \%$ of them are men. The distribution of patients by EDSS score at model entry is shown in Table I (average EDSS score: 2.72).

\section{Natural history}

Natural history of disease has been conventionally measured through two main parameters: i) annual incidence of relapses; ii) annual EDSS progression probabilities. Data on annual relapse rates (Table 1) were obtained from i) dimethyl fumarate clinical trials [23,24], documenting relapse occurrence in the 12 months before study entry for RRMS patients with EDSS score $\leq 5$; ii) from the study conducted by Patzold et al. [25], for RRMS patients with EDSS levels $>5$; iii) from the elaboration of a survey conducted in the UK [26], for patients affected by SPMS form.

Data on natural disease history (Supplementary Table I and Supplementary Table II), inform on how RRMS patients progress in disease severity in absence of treatment. They were elaborated from dimethyl fumarate clinical trials (CONFIRM, DEFINE [23,24]) and the London Ontario database, one of the most comprehensive and long-lasting observational registries on patients with multiple sclerosis [27-29].

Age- and sex-specific all-cause mortality rates for the general population were obtained from the Italian mortality tables [30]. These mortality rates were then adjusted by the MSrelated additional risk of death [31].

\section{Treatment efficacy}

Treatment with DMTs like dimethyl fumarate or teriflunomide modify the natural history of the disease, i.e. reduce incidence of relapses and delay disability progression, compared to no treatment/placebo. Estimates of treatment efficacy for both therapies vs. placebo were extracted from the Mixed Treatment Comparison (MTC) conducted by Hutchinson et al. [32]. The MTC calculated risk ratios for relapses and hazard ratios for disability progression, for

\begin{tabular}{lcccccccccc}
\hline \multicolumn{1}{c}{ Baseline data } & \multicolumn{10}{c}{ EDSS level } \\
\cline { 2 - 11 } & $\mathbf{0}$ & $\mathbf{1}$ & $\mathbf{2}$ & $\mathbf{3}$ & $\mathbf{4}$ & $\mathbf{5}$ & $\mathbf{6}$ & $\mathbf{7}$ & $\mathbf{8}$ & $\mathbf{9}$ \\
\hline $\begin{array}{l}\text { Proportion of patients (\%) } \\
\text { ARR (n of events per year) }\end{array}$ & 5.05 & 8.52 & 34.08 & 22.94 & 20.64 & 8.65 & 0.12 & 0.00 & 0.00 & 0.00 \\
RRMS form, natural history & 1.26 & 1.32 & 1.32 & 1.35 & 1.36 & 1.43 & 1.18 & 1.23 & 1.23 & 1.23 \\
SPMS form, natural history & 0.00 & 0.00 & 0.91 & 1.64 & 1.05 & 1.27 & 1.10 & 0.82 & 0.82 & 0.82 \\
\hline
\end{tabular}

Table I. Distribution of patients by EDSS at model entry and ARRs, in absence of treatment [23-29]

$\mathrm{ARR}=$ annualized relapse rate; EDSS = expanded disability status scale; RRMS = relapsing-remitting multiple sclerosis; SPMS = secondary progressive multiple sclerosis 


\begin{tabular}{lcc}
\hline \multicolumn{1}{c}{ Treatment } & $\begin{array}{c}\text { Disability progression at 12 weeks: } \\
\text { HR vs. placebo (Cl 95\%) }\end{array}$ & ARR: RR vs. placebo (Cl 95\%) \\
\hline Teriflunomide $-14 \mathrm{mg}$ daily & $0.7106(0.5736-0.8803)$ & $0.7113(0.6224-0.8129)$ \\
Dimethyl fumarate $-240 \mathrm{mg}$ twice daily & $0.6051(0.4713-0.7767)$ & $0.5269(0.4507-0.6159)$ \\
Placebo & Reference & Reference \\
\hline
\end{tabular}

Table II. Treatment efficacy vs. placebo for relapse rate and disability progression [32]

$\mathrm{ARR}=$ annualized relapse rate; $\mathrm{Cl}=$ confidence interval; $\mathrm{HR}=$ hazard ratio; $\mathrm{RR}=$ risk ratio

both dimethyl fumarate and teriflunomide, compared to placebo. Both treatment effect ratios on ARR and disability progression are summarized in Table II.

To model disability worsening, annual probabilities of disability progression, in absence of treatment (placebo) were used. Annual values were taken from: i) dimethyl fumarate clinical trials (CONFIRM, DEFINE [23,24]) for RRMS EDSS states up to 7; ii) from the London Ontario dataset [27] for RRMS EDSS states 7 to 9 and for the SPMS form (Supplementary Table I); iii) from the London Ontario dataset [27], for transition probabilities from RRMS to SPMS (Supplementary Table II).

\section{Adverse events}

Adverse events (serious and non-serious) occurring in $\geq 5 \%$ patients in dimethyl fumarate studies and with an incidence difference of $>3 \%$ between dimethyl fumarate and teriflunomide, were included in the analysis (Supplementary Table III). Annual incidence rates of treatment-related AEs were gathered from Hutchinson et al. systematic review and mixed treatment comparison [32]. Both effects and costs associated with AEs were analysed.

\begin{tabular}{ccc|cc}
\hline \multirow{2}{*}{ EDSS level } & \multicolumn{2}{c|}{ With relapses } & \multicolumn{2}{c}{ Without relapses } \\
\cline { 2 - 5 } & RRMS & SPMS & RRMS & SPMS \\
\hline 0 & 0.8660 & 0.8223 & 0.8752 & 0.8315 \\
1 & 0.8250 & 0.7814 & 0.8342 & 0.7905 \\
2 & 0.7710 & 0.7274 & 0.7802 & 0.7365 \\
3 & 0.6855 & 0.6418 & 0.6946 & 0.6509 \\
4 & 0.6161 & 0.5725 & 0.6253 & 0.5816 \\
5 & 0.5350 & 0.4913 & 0.5442 & 0.5005 \\
6 & 0.4463 & 0.4027 & 0.4555 & 0.4118 \\
7 & 0.3346 & 0.2909 & 0.3437 & 0.3000 \\
8 & -0.0068 & -0.0505 & 0.0023 & -0.0413 \\
9 & -0.1793 & -0.2229 & -0.1701 & -0.2138 \\
\hline
\end{tabular}

Table III. Utilities weights by EDSS level, MS form and relapse health state $[23,24,26]$

EDSS = expanded disability status scale; RRMS = relapsing-remitting multiple sclerosis; SPMS $=$ secondary progressive multiple sclerosis

\section{Quality of life data}

Utility weights for patients affected by RRMS, stratified by EDSS level (Table III), were obtained from dimethyl fumarate trials $[23,24]$ organizing the observations for each EDSS state and calculating the average EQ5D (EuroQoL, 5 dimensions) score for each state. Disutility values were applied to RRMS utility values to calculate utility weights in: i) SPMS health states (RRMS utility minus 0.0437); ii) relapse health states (RRMS utility minus 0.0092); iii) health states with AEs (RRMS utility minus the sum of specific disutility values of individual AEs).

Both disutility scores associated with SPMS and relapse were retrieved from the survey conducted in the UK [26] and apply on annual basis (entire cycle duration). AErelated disutilities depend on the type and se-

\begin{tabular}{|c|c|c|c|c|c|c|c|c|c|c|}
\hline \multirow{2}{*}{ Costs $(€)^{1}$} & \multicolumn{10}{|c|}{ EDSS level } \\
\hline & 0 & 1 & 2 & 3 & 4 & 5 & 6 & 7 & 8 & 9 \\
\hline \multicolumn{11}{|c|}{ Societal perspective } \\
\hline RRMS & 4,609 & 4,609 & 4,609 & 4,609 & 20,969 & 20,969 & 20,969 & 38,971 & 38,971 & 38,971 \\
\hline SPMS & 10,070 & 10,070 & 10,070 & 10,070 & 45,811 & 45,811 & 45,811 & 85,137 & 85,137 & 85,137 \\
\hline \multicolumn{11}{|c|}{ NHS perspective } \\
\hline RRMS & 2,382 & 2,382 & 2,382 & 2,382 & 7,636 & 7,636 & 7,636 & 8,633 & 8,633 & 8,633 \\
\hline SPMS & 5,204 & 5,204 & 5,204 & 5,204 & 16,681 & 16,681 & 16,681 & 18,861 & 18,861 & 18,861 \\
\hline
\end{tabular}

Table IV. Annual disability-related costs, by MS form and perspective [33,34]

${ }^{1}$ Relating to RRMS form and EDSS levels $<7$, to avoid double counting DMT costs, disease management costs (e.g. monitoring, etc.) were subtracted from this calculation and considered in other calculation sections of the model

EDSS = expanded disability status scale; NHS = National Healthcare Service; RRMS = relapsing remitting multiple sclerosis; SPMS = secondary progressive multiple sclerosis 
verity of the AE itself, and have a temporary effect on patients' quality of life (from a minimum of one day per year, up to a maximum of six months per year, for some events such as fatigue and flu-like symptoms) and are reported in Supplementary Table III. Since AE-related disutilities were not available in literature, they were estimated and validated by clinical experts.

\section{Economic data}

The economic analysis was conducted adopting the societal perspective and considering the following costs: i) treatment with DMTs; ii) administration; iii) monitoring; iv) adverse events; v) relapses; vi) EDSS.

Disability-related costs, including indirect costs (loss of work productivity and absenteeism), were obtained from an elaboration of the data of the study conducted by Battaglia et al. 2017 [33] and Karampampa et al. [34]. Table IV shows disability-related annual costs included in the model, expressed in Euro and inflated from 2015 to February 2020 (coefficient 1.026) [35].

Annual treatment costs with DMTs (dimethyl fumarate and teriflunomide) were calculated using the ex-factory prices per pack (Table V), including the temporary law reductions and discounts granted to the Italian National Healthcare Service (NHS), multiplied by the number of packs needed to cover 1 year of treatment. No administration costs were included, as both drugs are administered orally. Annual monitoring costs were calculated assuming that patients would be compliant with main recommendations for the follow-up of RRMS [36,37] (Table $\mathrm{V}$ ). These costs take into account the number of annual examinations (magnetic resonance imaging, blood count, kidney and liver function, etc.) and annual visits (neurological).

The cost of relapse management (cost per episode) was obtained from Battaglia et al. 2017 $(€ 2,600$ and $€ 1,497$, respectively for societal and NHS perspectives, in December 2015 [33]) and then inflated from 2015 to February 2020 ( $€ 2,668$ and $€$ 1,536, respectively; coefficient 1.026) [35]. Finally, treatment-related adverse event costs were calculated by multiplying the unit costs in the Italian practice (Supplementary Table V), by the respective annual incidence rates of treatment-related AEs (Supplementary Table III).

It was assumed that mild-to-moderate events were managed either by general practitioners (GPs) [38] or specialized neurologists [39], while severe events were managed in the hospital setting (either day-hospital or standard admission [40,41], depending on the event). All economic inputs are summarized in Table V.

\section{Additional analyses on time horizon and clinical outcomes}

A supplementary analysis was carried out to assess ICER variability over time, in both Italian NHS and societal perspectives.

Further analyses were conducted to compare the clinical effectiveness of the two treatments over the time horizon, in terms of: i) incidence relapse rates; ii) percentage of patients with EDSS score $\leq 3$; iii) percentage of patients with EDSS score $\geq 6$.

\section{Sensitivity analyses}

Both univariate deterministic and multivariate probabilistic sensitivity analyses were conducted to identify model parameters with the largest effect on incremental cost-effectiveness ratio (ICER), and to evaluate the overall robustness of the base-case analysis.

For the deterministic sensitivity analysis, the baseline value of each parameter (dimethyl fumarate relapse rate, dimethyl fumarate disability progression rate, teriflunomide relapse rate, teriflunomide disability progression rate) was modified to the upper and lower limits of its $95 \%$ confidence inter-

\begin{tabular}{|c|c|c|}
\hline Description of costs & Value $(€)$ & Source/Note \\
\hline \multicolumn{3}{|l|}{ Drug acquisition costs } \\
\hline Dimethyl fumarate & $\begin{array}{c}1,153.00 \\
(56 \text { capsules, } 240 \mathrm{mg})\end{array}$ & $\begin{array}{c}\text { Ex-factory price }{ }^{1} \\
\text { (Official Journal 19, } \\
2015[13] \text { ) }\end{array}$ \\
\hline Teriflunomide & $\begin{array}{c}1,027.75 \\
(28 \text { tablets, } 14 \mathrm{mg})\end{array}$ & $\begin{array}{c}\text { Ex-factory price }^{1} \\
\text { (Official Journal 187, } \\
2014 \text { [15]) }\end{array}$ \\
\hline \multicolumn{3}{|l|}{ Administration costs } \\
\hline Dimethyl fumarate & 0.00 & \multirow{2}{*}{$\begin{array}{c}\text { Assumption, as both } \\
\text { drugs are administered } \\
\text { orally }\end{array}$} \\
\hline Teriflunomide & 0.00 & \\
\hline \multicolumn{3}{|l|}{ Monitoring costs } \\
\hline Dimethyl fumarate (Year 1) & 912 & \multirow{4}{*}[36,37]{} \\
\hline Teriflunomide (Year 1) & 977 & \\
\hline Dimethyl fumarate (Year 2) & 334 & \\
\hline Teriflunomide (Year 2) & 350 & \\
\hline \multicolumn{3}{|l|}{ Adverse events costs } \\
\hline Dimethyl fumarate & 32 & \multirow{2}{*}{$\begin{array}{c}\text { Mild to moderate: GP } \\
\text { [38] or specialist [39] } \\
\text { visit; Severe: DH or } \\
\text { hospital admission } \\
{[40,41]}\end{array}$} \\
\hline Teriflunomide & 11 & \\
\hline $\begin{array}{l}\text { Relapse management } \\
\text { costs }\end{array}$ & 2,668 & $\begin{array}{c}\text { Battaglia et al. } 2017 \\
\text { [33], expressed in Euro } \\
\text { (February 2020) [35] }\end{array}$ \\
\hline
\end{tabular}

Table V. Economic data included in the analysis

${ }^{1}$ It does not include temporary law reductions and any discounts applied to public structures of Italian NHS

$\mathrm{DH}=$ day hospital; DMT = disease-modifying therapies; GP = general practitioner 
val $(95 \% \mathrm{CI})$. If the CI was not available, a variation of $\pm 10 \%$ from the baseline value (EDSS state costs, relapse costs, patient utilities, natural history relapse rates) was used.

Three additional deterministic sensitivity analyses were conducted. In the first analysis, the Italian NHS perspective was adopted with lifetime horizon. In the second and third analyses, a shorter time horizon was used (15 years) to run both the Italian societal perspective and the Italian NHS perspective analyses.

For the probabilistic analysis, the following distributions were used: lognormal for clinical variables (relapse rates, progression rates and utilities); beta for EDSS transition probabilities to SPMS form and adverse event rates; gamma for costs. A $10 \%$ standard error of the mean value of each variable was used to run probabilistic sensitivity analysis.

\section{RESULTS}

\section{Base-case}

In the base-case analysis (societal perspective and lifetime horizon), dimethyl fumarate was more effective than teriflunomide, both in terms of survival (19.634 and 19.547 life years, LYs, respectively), and quality-of-life-adjusted survival (6.526 and 5.953 QALYs, respectively). The total lifetime cost per patient treated with dimethyl fumarate $(€ 1,010,112)$ was lower than the cost per patient treated with teriflunomide $(€ 1,030,436)$.

Therefore, dimethyl fumarate was dominant (i.e. more effective and less costly) compared with teriflunomide. Table VI illustrates the results of the cost-effectiveness analysis.

The cost saving for patient treated with dimethyl fumarate vs teriflunomide was $€ 20,324$. The saving is mainly evident on cost of relapses $(-€ 5,096)$, inpatient care $(-€ 5,767)$, informal care $(-€ 9,604)$ and long-term absence/early retirement (-€ 14,187).

\section{Additional analyses on time horizon and clinical outcomes}

The results of ICER assessment by time horizon and perspective showed that dimethyl fumarate was cost-effective vs. teriflunomide (i.e. ICER $<€ 50,000$ per QALY gained) at already

\begin{tabular}{|c|c|c|c|}
\hline Item & Dimethyl fumarate (A) & Teriflunomide (B) & Difference (A-B) \\
\hline \multicolumn{4}{|l|}{ Outcome } \\
\hline LYS & 19.634 & 19.547 & 0.087 \\
\hline QALYS & 6.526 & 5.953 & 0.573 \\
\hline \multicolumn{4}{|l|}{ Costs $(€)$} \\
\hline Treatment costs ${ }^{1}$ & 94,637 (9.36\%) & 72,608 (7.05\%) & $22,030.04$ \\
\hline Adverse events & $261(0.03 \%)$ & 87 (0.01\%) & 173.41 \\
\hline Relapse $^{2}$ & $43,943(4.35 \%)$ & 49,039 (4.76\%) & $-5,096.37$ \\
\hline EDSS $^{2}$ & $871,271.12$ & $908,702.46$ & $-37,431.35$ \\
\hline Inpatient care & 136,387 (13.50\%) & $142,154(13.80 \%)$ & $-5,766.69$ \\
\hline Day admission & 34,508 (3.42\%) & $35,290(3.42 \%)$ & -782.29 \\
\hline Consultations & 23,957 (2.37\%) & 24,795 (2.41\%) & -838.21 \\
\hline Tests & $12,826(1.27 \%)$ & $12,772(1.24 \%)$ & 53.81 \\
\hline Medication & 20,817 (2.06\%) & $21,461(2.08 \%)$ & -644.19 \\
\hline Community service & $83,676(8.28 \%)$ & $88,014(8.54 \%)$ & $-4,338.27$ \\
\hline Investments & $29,022(2.87 \%)$ & 30,347 (2.95\%) & $-1,324.94$ \\
\hline Informal care & 208,419 (20.63\%) & $218,022(21.16 \%)$ & $-9,603.54$ \\
\hline $\begin{array}{l}\text { Absence, invalidity and early } \\
\text { retirement }\end{array}$ & 321,661 (31.84\%) & 335,848 (32.59\%) & $-14,187.04$ \\
\hline Total social costs & $1,010,112(100.00 \%)$ & $1,030,436(100.00 \%)$ & $-20,324.26$ \\
\hline ICER (€/QALY gained) & & Dimethyl fumarate dominant & \\
\hline
\end{tabular}

Table VI. Results of the incremental cost-effectiveness analysis (base-case: societal perspective and lifetime horizon) ${ }^{1}$ Including monitoring costs

${ }^{2}$ Including direct and indirect costs

EDSS = expanded disability status scale; ICER = incremental cost-effectiveness ratio; LYs = life-years; QALYS = quality-adjusted life years 


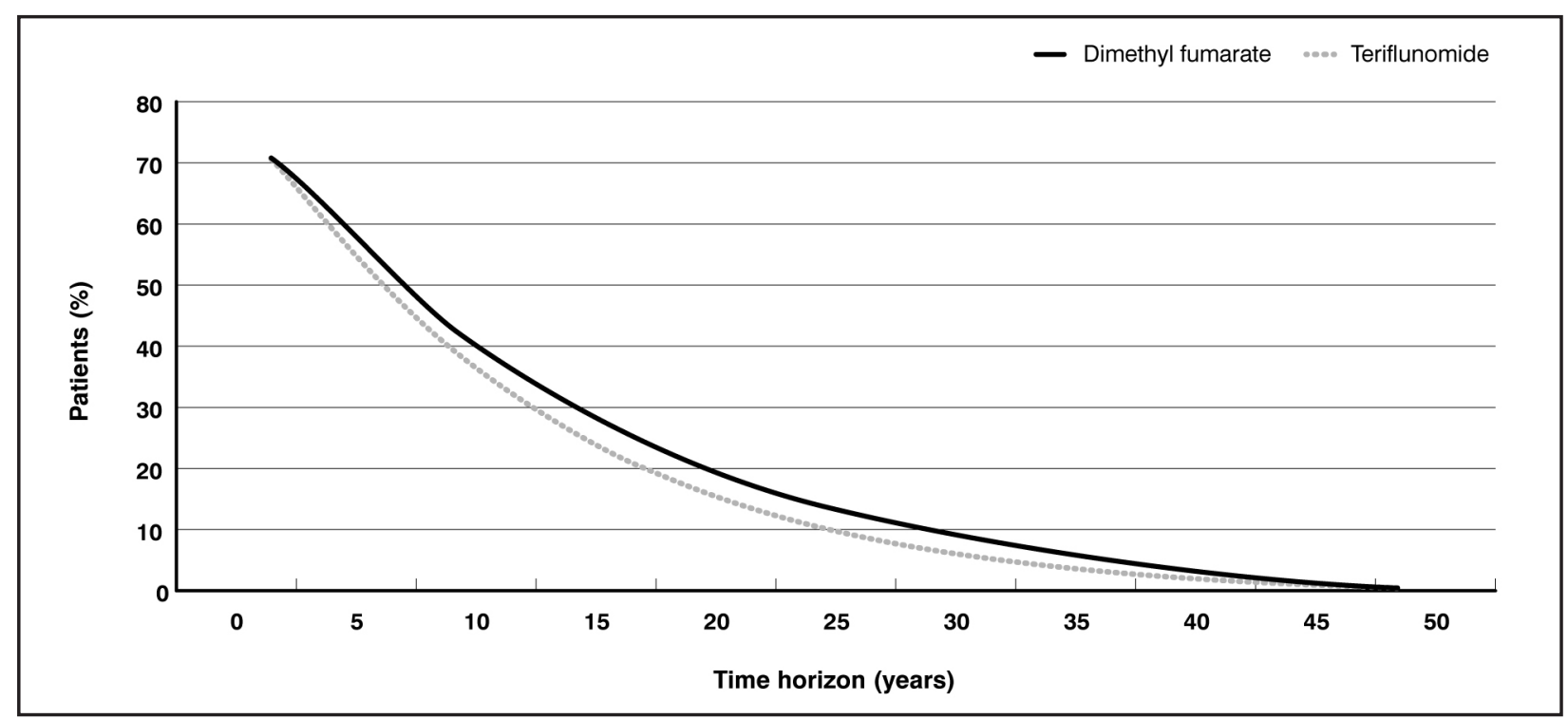

Figure 2. Proportion of patients with mild disability (EDSS $\leq 3$ ), over time horizon used in the economic model

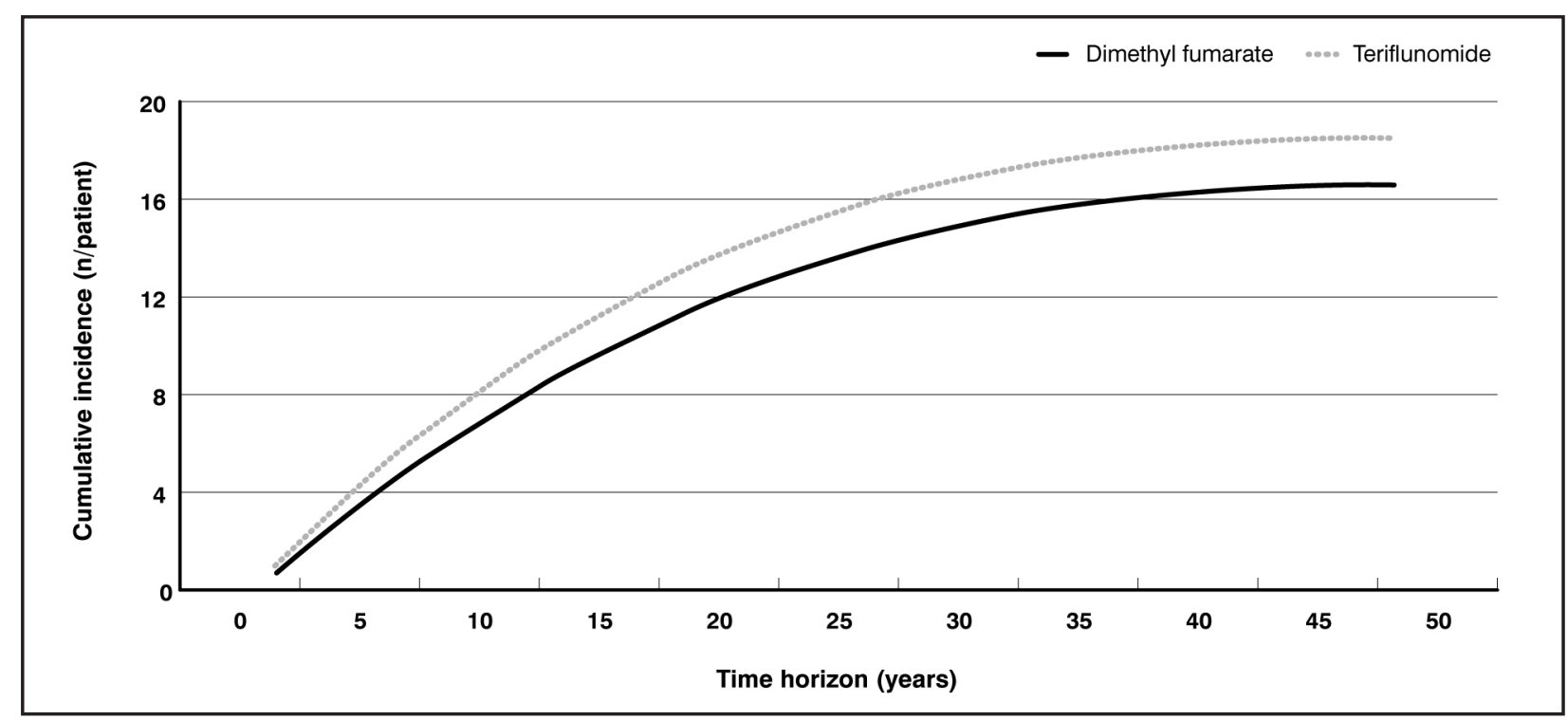

Figure 3. Incidence of relapses over time horizon used in the economic model

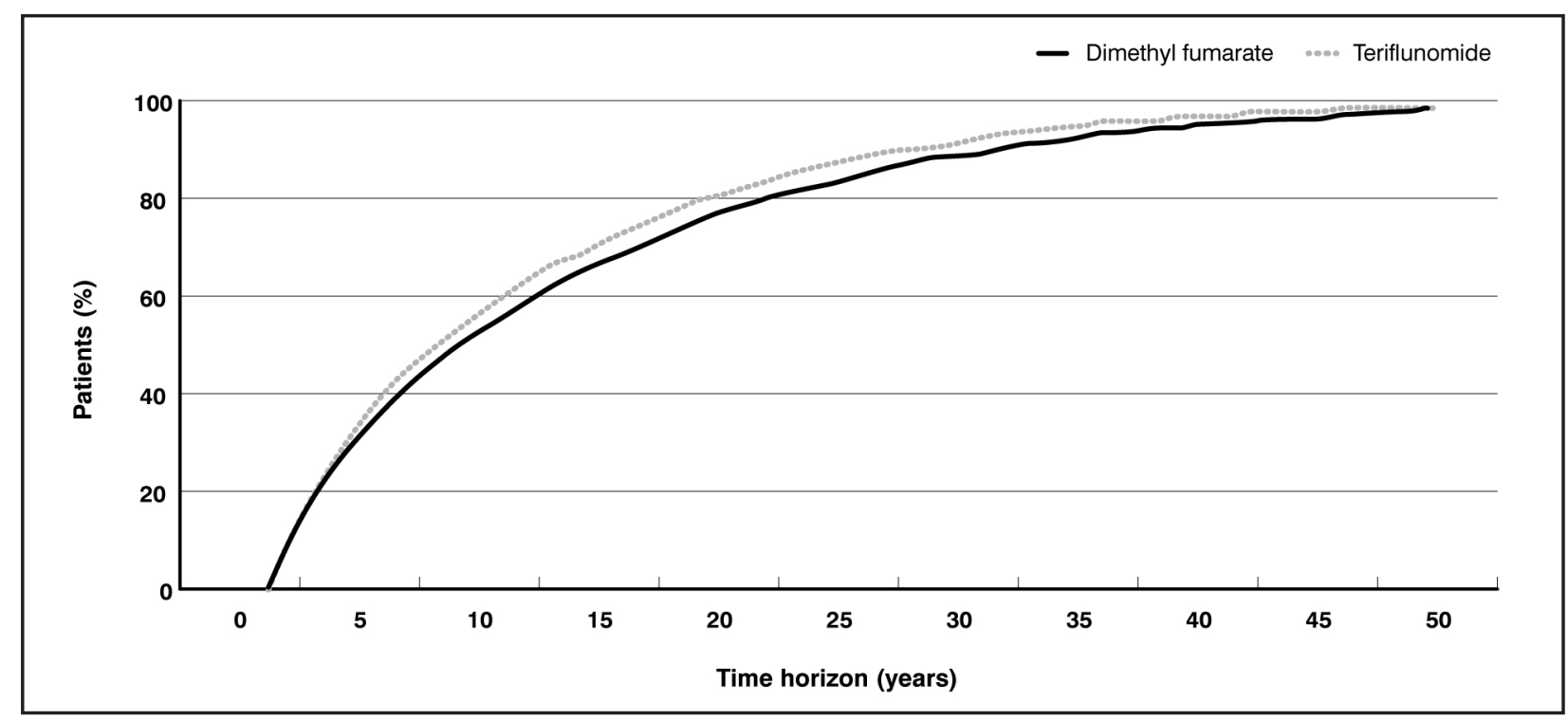

Figure 4. Proportion of patients with severe disability (EDSS $\geq 6$ ), over time horizon used in the economic model EDSS $=$ expanded disability status scale 
6 years, if the societal perspective is adopted, and at 15 years, if the Italian NHS perspective is adopted.

The model also informed on several patient-relevant outcomes such burden of relapses and life years with mild/severe disability (EDSS $\leq 3$; EDSS $\geq 6$ ). The onset of relapse benefit with dimethyl fumarate occurred quite earlier in time, during the first years of treatment with $-0,23$ relapse per patient (Figure 3). For instance, at 10 years, patients treated with dimethyl fumarate experienced -1.37 relapses less than patients treated with teriflunomide, which translated into $4 \%$ more patients with reduced disability (EDSS $\leq 3$ ). Then, the benefit (i.e. higher proportion of patients with mild EDSS) has been stable up to year 25, while decreasing afterwards (because of combined effect of disease progression, SPMS transition, and mortality) (Figure 2). The proportion of patients with severe disability (EDSS $\geq 6$ ), treated with dimethyl fumarate was lower than that treated with teriflunomide already after 3 years from model simulation, and remained steadily lower until about the $35^{\text {th }}$ year (Figure 4).

\section{Sensitivity analysis}

One-way deterministic sensitivity analysis showed that dimethyl fumarate was dominant in all tested alternative scenarios, excluding the case of use of the lower limit of the $95 \% \mathrm{CI}$ for teriflunomide disability progression rate. Moreover, dimethyl fumarate remained cost-effective compared with teriflunomide in the three additional deterministic scenarios tested, with an incremental cost effectiveness ratio ICER below the willingness-to-pay (WTP) threshold of $€ 50,000$ per QALY gained (Table VII).

Figure 5 shows the results of probabilistic sensitivity analysis performed on the base-case, expressed as probability of dimethyl fumarate to be cost-effective or dominant with respect to teriflunomide, below a WTP threshold of $€ 50,000$ per QALY gained.

The acceptability curve of the cost-effectiveness analysis (CEAC, Figure 5) shows that when the willingness to pay (WTP) was $€ 50,000$ per QALY gained, dimethyl fumarate had $78 \%$ probability of being cost-effective compared to teriflunomide, based on societal per-

\begin{tabular}{cccc}
\hline $\begin{array}{c}\text { Alternative } \\
\text { Scenario }\end{array}$ & Perspective & Time horizon & $\begin{array}{c}\text { ICER (€/QALY } \\
\text { gained) }\end{array}$ \\
\hline$\# 11$ & Italian NHS & Lifetime & $19,691.41$ \\
$\# 2$ & Societal & 15 years & $\begin{array}{r}-25,348.32 \\
\text { Dominant }\end{array}$ \\
$\# 3$ & Italian NHS & 15 years & $41,189.50$ \\
\hline
\end{tabular}

Table VII. Sensitivity analysis: results of alternative scenarios ${ }^{1}$ Supplementary Table V

ICER $=$ incremental cost-effectiveness ratio; NHS = National Healthcare Service; QALY = quality-adjusted life years spective and lifetime horizon. In $72 \%$ of the iterations, dimethyl fumarate was dominant over teriflunomide.

Figure 6 shows the results of probabilistic sensitivity analysis performed on the alternative scenario \#1 (NHS perspective and lifetime horizon). The CEAC shows that when the WTP was $€ 50,000$ per QALY gained, dimethyl fumarate had $68 \%$ probability of being cost-effective compared to teriflunomide, based on NHS perspective and lifetime horizon.

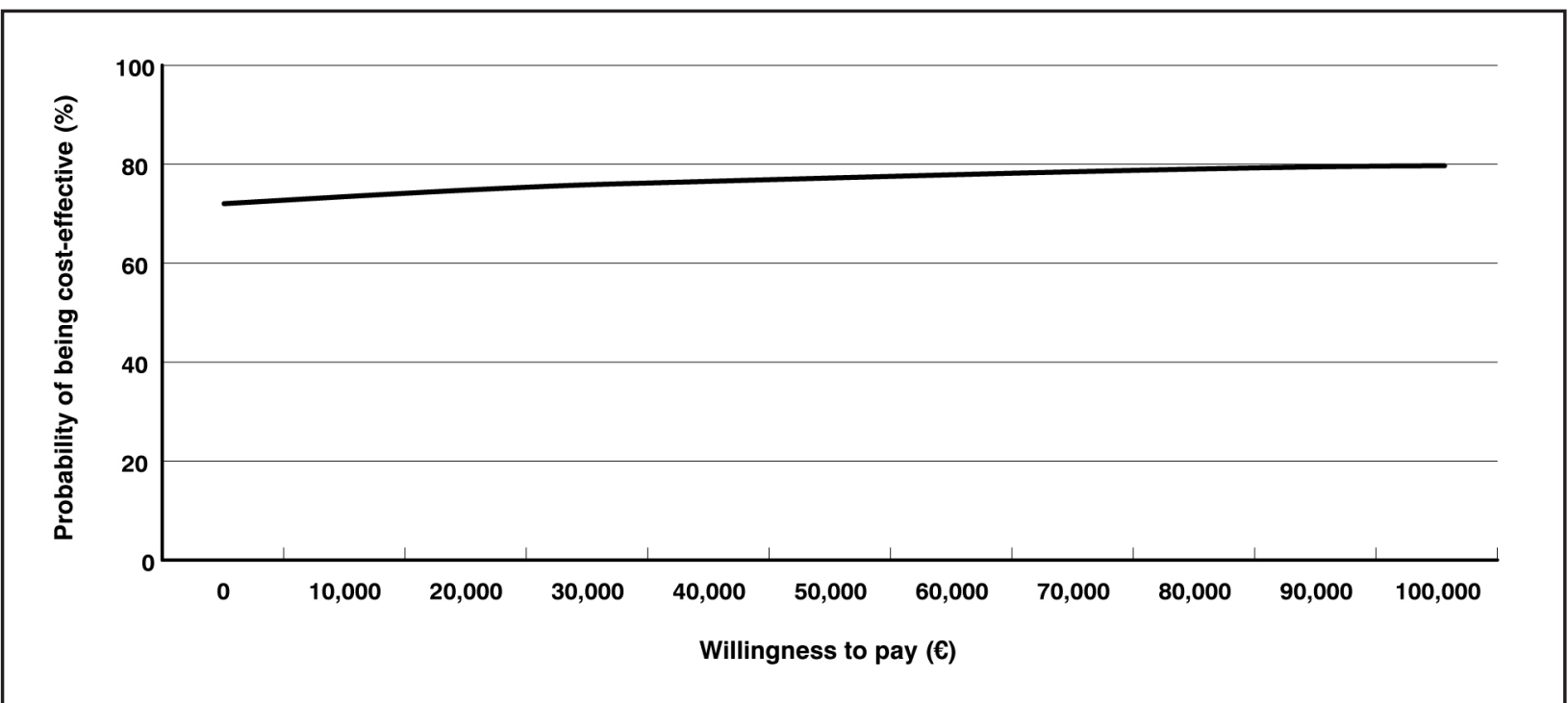

Figure 5. Probabilistic sensitivity analysis: acceptability curve of dimethyl fumarate vs. teriflunomide (base-case: societal perspective and lifetime horizon) 


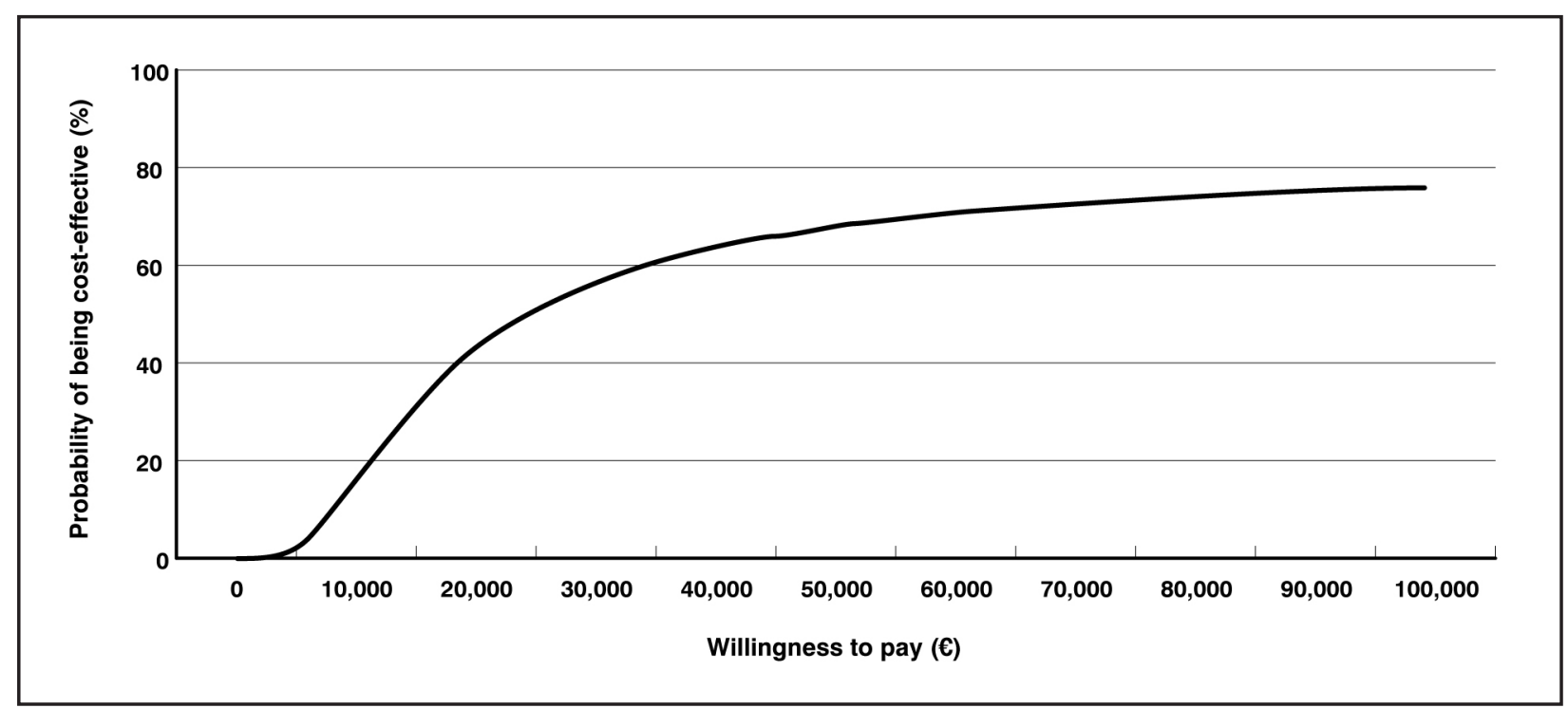

Figure 6. Probabilistic sensitivity analysis: acceptability curve of dimethyl fumarate vs. teriflunomide (alternative scenario \#1: NHS perspective and lifetime horizon)

\section{DISCUSSION}

With this analysis, we aimed to compare costs and outcomes of dimethyl fumarate and teriflunomide, two oral DMTs indicated as first-line treatment of RRMS. The results of this 1:1 comparison showed that dimethyl fumarate was cost-effective vs. teriflunomide for the treatment of RRMS.

In fact, dimethyl fumarate was dominant (i.e. lower costs and better health outcomes) in the societal perspective analysis and remained highly cost-effective vs. teriflunomide (ICER $<€ 50,000$ QALY gained), when the Italian NHS perspective was considered. In base-case, dimethyl fumarate was more effective than teriflunomide, both in terms of survival (19.634 and 19.547 LYs, respectively), and quality-of-life-adjusted survival (6.526 and 5.953 QALYs, respectively). The total lifetime cost per patient treated with dimethyl fumarate $(€ 1,010,112)$ was lower than the cost per patient treated with teriflunomide $(€ 1,030,436)$.

In this analysis, we chose to set up a base-case looking at the societal perspective, because we wanted to capture the entire spectrum of costs (including out-of-pocket expenses, reduced/ lost productivity, formal and informal caregiving, home adaptations, etc.), which are extremely relevant for conditions like multiple sclerosis, as shown in literature [7,33,34]. Interestingly, our analysis shows that less than $10 \%$ of social costs are allocated to pharmacological treatments, and that other costs drive the economic burden (absence from work, invalidity and early retirement; informal care; inpatient care costs; community service; relapse).

Nonetheless, we also conducted additional analyses reflecting the Italian NHS perspective, as we are aware of the importance of such perspective for budget holders in charge of drug decision making, and of the importance of demonstrating consistent cost-effectiveness of one technology when a subset of costs (direct costs, i.e., drug acquisition, monitoring, adverse events, tests and medication) is considered.

These additional analyses confirmed findings of the base-case analysis, with dimethyl fumarate being cost-effective vs. teriflunomide with an acceptable ICER. Even if no economic acceptability threshold has been officially defined in Italy to date, some proposals have been formulated by some Italian authors [42-45]. In other countries official thresholds are used [22] or thresholds are proposed by authors or organizations [46,47]. For this analysis it was preferred to use the same acceptability threshold used in other dimethyl fumarate economic analyses published in Italy [20,48].

Finally, the results of deterministic and probabilistic sensitivity analyses confirm the reliability and robustness of base-case results.

Although we were aware this was a cost-effectiveness assessment, we wanted to provide a more detailed analyses of the clinical outcomes derived from the model simulation. Together with the standard indicators shown in pharmacoeconomic analyses (quality adjusted survival, costs, incremental cost-effectiveness ratios), some additional outcomes were analysed and reported, to investigate the clinical rationale behind the incremental benefit associated with dimethyl fumarate. A conjoint analysis of four indicators, quality adjusted survival, burden 
of relapses and life years with mild (EDSS $\leq 3)$ and severe (EDSS $\geq 6$ ) disability is useful to understand the model dynamics and the reason for the clinical benefit. All in all, dimethyl fumarate patients have fewer relapses than teriflunomide patients, which translates into an earlier benefit of reduced disease activity and reduced proportion of patients progressing severe health states. This "early benefit", observed in our simulations since the first years since treatment initiation, transforms into a quality-adjusted survival benefit later in time. In other words, early prevention of relapses delays disability, whose negative effects will be observed later (e.g. due to detrimental quality of life for disease mobility, social functioning, isolation, etc.). These results are driven by the clinical efficacy data used in the model, coming from Hutchinson et al. mixed treatment comparison (MTC) [32], which demonstrate that dimethyl fumarate is statistically superior to teriflunomide in preventing relapses and numerically superior to teriflunomide in delaying disability progression.

MTC results [32] have been confirmed by the results of two real world studies: i) Braune et al. 2018 [49] study that compared dimethyl fumarate versus teriflunomide and other treatments, evaluating the time to first relapse (TTFR) and annualised relapse rate (ARR); ii) Buron et al. 2019 [50] study that compared on-treatment efficacy and discontinuation outcomes in teriflunomide and dimethyl fumarate. In the first study, both outcomes were better in the population treated with dimethyl fumarate compared to teriflunomide; in the second study, a higher relapse-free survival and a lower incidence of discontinuation due to disease breakthrough on treatment with dimethyl fumarate vs. teriflunomide were showed.

From a methodological point of view, this analysis is a revised and updated version of previous cost-effectiveness assessments on the use of dimethyl fumarate as first-line treatment of the RRMS $[20,48]$. Compared with these previous analyses, the most relevant update consists in the choice of the economic data (source for EDSS costs and updating prices). Given the similarities on methodological approach and model framework, the present analysis is affected by the same limitations that have been extensively reported in previous publications $[20,48]$. In summary, the lack of one head-to-head study comparing dimethyl fumarate vs. teriflunomide, the impossibility of testing treatment sequences (i.e. add-up a second-line treatment after failure with first-line treatment), the lack of a systematic approach in including all treatment-related adverse events, and finally the lack of quantification of MS intangible costs are the main limitations of the study. As said, a detailed analysis of such limitations and their impact on results has been conducted and documented in previous publications [20,48]. However, the consistent findings from deterministic and probabilistic analyses, together with the additional scenarios, give high level of confidence with regards of analysis robustness.

This assessment intends to support decision makers in their decision on drug access and physicians on appropriate prescription. For the latter, of course, a cost-effectiveness cannot be a tool for decision making, because it does not capture many aspects of the disease and more importantly, because all the patients are different and have different needs, perception, history, etc. However, we believe these types of evaluation can provide prescribers with a "piece of information" that can play a role in the final treatment decision.

\section{CONCLUSIONS}

The results of the cost-effectiveness analysis confirm that dimethyl fumarate is an optimal first-line treatment for RRMS compared to teriflunomide in both Italian NHS and societal perspectives and considering a lifetime horizon. In the base-case analysis dimethyl fumarate is dominant (more effective and less costly) compared with teriflunomide. The additional analysis of ICER by time horizon shows that dimethyl fumarate is at least cost-effective option vs teriflunomide (i.e. ICER $<€ 50,000$ per QALY gained) in societal and NHS perspectives. Results favoured dimethyl fumarate also for less cumulative burden of relapses, higher proportion of patients with EDSS $\leq 3$ and lower with EDSS $\geq 6$ at 10 years. This assessment can support decision makers but also prescribers in their decision.

\section{Acknowledgement}

The authors are grateful to Gianluca Furneri and Rossella Bitonti (EBMA Consulting) for supporting the development of the economic evaluation and the drafting of the manuscript

\section{Funding}

Biogen Italia (Milan, Italy) provided funding for pharmacoeconomic support on the development of the analysis. 


\section{Conflicts of interest}

LGM declares research grant from Biogen, Almirall, Roche, Bayer. Speaker's fee from Almirall, Roche, Biogen, Bayer.

PAC declares research grant from Angelini. Speaker's fee from Pfizer, Roche.

$A C$ and $L S$ are employees of Biogen Italia.

LP declares consulting fees from Biogen, Merck, Novartis and Roche; speaker honoraria from Biogen, Genzyme, Merck Serono, Novartis, Roche and Teva; travel grants from Biogen, Genzyme, Novartis,

Roche and Teva; research grants from the Italian MS Society (Associazione Italiana Sclerosi Multipla) and Genzyme.

\section{REFERENCES}

1. Walton C, King R, Rechtman L, et al. Rising prevalence of multiple sclerosis worldwide: Insights from the Atlas of MS, third edition. Mult Scler 2020; 26: 1816; https://doi. org/10.1177/1352458520970841

2. Italian Ministry of Health. Multiple Sclerosis. Available at: http:/www.salute.gov.it/portale/salute/p1_5.jsp?lingua=italiano\&id=177\&area=Malattie_del_sistema_nervoso (last accessed )

3. Associazione Italiana Sclerosi Multipla (AISM): BAROMETRO della SCLEROSI MULTIPLA 2019. Available at: https://www.aism.it/sites/default/files/Barometro_della_SM_2019estratto.pdf (last accessed)

4. Huang WJ, Chen WW, Zhang X. Multiple sclerosis: Pathology, diagnosis and treatments (review). Exp Ther Med 2017; 13: 3163-6; https://doi.org/10.3892/etm.2017.4410

5. Wallin MT, Culpepper WJ, Nichols E, et al. Global, regional, and national burden of multiple sclerosis 1990-2016: a systematic analysis for the Global Burden of Disease Study 2016. Lancet Neurol 2019; 18: 269-85; https://doi.org/10.1016/S1474-4422(18)30443-5

6. Kobelt G, Thompson A, Berg J, et al. New insights into the burden and costs of multiple sclerosis in Europe. Mult Scler 2017; 23: 1123-36; https://doi.org/10.1177/1352458517694432

7. Kobelt G, Berg J, Lindgren P, et al. Costs and quality of life of patients with multiple sclerosis in Europe. J Neurol Neurosurg Psychiatry 2006; 77: 918-26; https://doi.org/10.1136/ jnnp.2006.090365

8. Phillips CJ, Humphreys I. Assessing cost-effectiveness in the management of multiple sclerosis. Clinicoecon Outcomes Res 2009; 1: 61-78; https://doi.org/10.2147/CEOR.S4225

9. Dutta R, Trapp BD. Relapsing and progressive forms of multiple sclerosis - insights from pathology. Curr Opin Neurol 2015 ;27: 271-8; https://doi.org/10.1097/ WCO.0000000000000094

10. Tremlett HL, Oger J. Interrupted therapy: Stopping and switching of the $\beta$-interferons prescribed for MS. Neurology 2003; 61: 551-4; https://doi.org/10.1212/01.WNL.0000078885.05053.7D

11. Mehr SR, Zimmerman MP. Reviewing the unmet needs of patients with multiple sclerosis. Am Heal Drug Benefits 2015; 8: 426-31

12. Miller AE, Rhoades RW. Treatment of relapsing-remitting multiple sclerosis: current approaches and unmet needs. Curr Opin Neurol 2012; 25: S4-10; https://doi.org/10.1097/01. wco.0000413319.87092.19

13. Italian Medicines Agency (AIFA). Reimbursement and selling price of new packages of Tecfidera. Official Journal n. 19 of the Italian Republic of January 12, 2015

14. European Medicines Agency (EMA). Dimethyl-fumarate (Tecfidera). Summary of product characteristics. Available at: http://www.ema.europa.eu/docs/en_GB/document_library/ EPAR__Product_Information/human/002601/WC500162069.pdf (last accessed...)

15. Italian Medicines Agency (AIFA). Reimbursement and selling price of new packages of Aubagio. Official Journal n. 187of the Italian Republic of August 13, 2014

16. European Medicines Agency (EMA). Teriflunomide (Aubagio). Summary of product characteristics. Available at: http://www.ema.europa.eu/docs/en_GB/document_library/ EPAR___Product_Information/human/002514/WC500148682.pdf (last accessed...) 
17. National Institute for Health and Care Excellence (NICE). Beta interferon and glatiramer acetate for the treatment of multiple sclerosis. Available at: https:/www.nice.org.uk/guidance/ta32 (last accessed September 2018)

18. National Institute for Health and Care Excellence (NICE). Fingolimod for the treatment of highly active relapsing-remitting multiple sclerosis. Available at: https:/www.nice.org.uk/ guidance/ta254 (last accessed September 2018)

19. Gani R, Giovannoni G, Bates D, et al. Cost-effectiveness analyses of natalizumab (Tysabri ${ }^{\circledR}$ ) compared with other disease-modifying therapies for people with highly active relapsingremitting multiple sclerosis in the UK. Pharmacoeconomics 2008; 26: 617-27; https://doi. org/10.2165/00019053-200826070-00008

20. Furneri G, Santoni L, Marchesi C, et al. Cost-effectiveness analysis of delayed-release dimethyl-fumarate in the treatment of relapsing-remitting multiple sclerosis in Italy. Farmeconomia. Health economics and therapeutic pathways 2016; 17: 67-80; https://doi. org/10.7175/fe.v17i2.1251

21. Kurtzke JF. A new scale for evaluating disability in multiple sclerosis. Neurology 1955; 5: $580-3$

22. National Institute for Health and Care Excellence (NICE). Guide to the methods of technology appraisal 2013. Available at: http://www.nice.org.uk/article/pmg9/chapter/foreword (last accessed September 2018)

23. Gold R, Kappos L, Arnold DLet al. Placebo-Controlled Phase 3 Study of Oral BG-12 for Relapsing Multiple Sclerosis. N Engl J Med 2012; 367: 1098-107; https://doi.org/10.1056/ NEJMoa1114287

24. Fox RJ, Miller DH, Phillips JT, et al. Placebo-controlled phase 3 study of oral BG-12 or glatiramer in multiple sclerosis. N Engl J Med. 2012; 367: 1087-97; https://doi.org/10.1056/ NEJMoa1206328

25. Patzold U, Pocklington PR. Course of multiple sclerosis. First results of a prospective study carried out of 102 MS patients from 1976-1980. Acta Neurol Scand 1982; 65: 248-66

26. UK Multiple Sclerosis Survey. Patient demographics, regression model on EDSS, relapse, type of MS and other variables on utility derived from EQ-5D. 2007.

27. Weinshenker BG, Bass B, Rice GPA, et al. The Natural History Of Multiple Sclerosis: A Geographically Based Study. Brain 1989; 112: 133-46; https://doi.org/10.1093/brain/112.6.1419

28. Kremenchutzky M, Rice GPA, Baskerville J, et al. The natural history of multiple sclerosis: A geographically based study 9: Observations on the progressive phase of the disease. Brain 2006; 129: 584-94; https://doi.org/10.1093/brain/awh721

29. Cottrell DA, Kremenchutzky M, Rice GP, et al. The natural history of multiple sclerosis: a geographically based study. 5. The clinical features and natural history of primary progressive multiple sclerosis. Brain 1999; 122: 625-39

30. National Institute of Statistics of Italy (ISTAT). Mortality rates, 2018. Available at: http:// demo.istat.it/tvm2016/index.php?lingua=ita (last accessed...)

31. Pokorski RJ. Long-term survival experience of patients with multiple sclerosis. $J$ Insur Med 1997; 29: 101-6.

32. Hutchinson M, Fox RJ, Havrdova E, et al. Efficacy and safety of BG-12 (dimethyl fumarate) and other disease-modifying therapies for the treatment of relapsing-remitting multiple sclerosis: a systematic review and mixed treatment comparison. Curr Med Res Opin 2014; 30: 613-27; https://doi.org/10.1185/03007995.2013.863755

33. Battaglia M, Kobelt G, Ponzio M, et al. New insights into the burden and costs of multiple sclerosis in Europe: Results for Italy. Mult Scler 2017; 23: 104-16; https://doi. org/10.1177/1352458517708176

34. Karampampa K, Gustavsson A, Miltenburger C et al. Treatment experience, burden and unmet needs (TRIBUNE) in MS study: results from five European countries. Mult Scler. 2012; 18: 7-15; https://doi.org/10.1177/1352458512441566

35. National Institute of Statistics of Italy (ISTAT). Inflation rates. Available at: http://rivaluta. istat.it/Rivaluta/ (last accessed September 2018) 
36. De Angelis F, John NA, Brownlee WJ. Disease-modifying therapies for multiple sclerosis. BMJ 2018; 363: k4674; https://doi.org/10.1136/bmj.k4674

37. Clinical expert opinion to determine monitoring costs associated to multiple sclerosis disease modifying therapies. Data on file. 2020

38. Garattini. Duration and costs of general practitioners' visits: the DYSCO project. Farmeconomia e percorsi terapeutici 2003; 4: 109-14; https://doi.org/10.7175/fe.v4i2.773

39. Italian Ministry of Health (2013). Outpatient intervention tariffs. Italian Republic Official Gazette. Chapter n. 23; Supplement n. 8; 28 January 2013

40. Italian Ministry of Health, Department of Planning of the National Healthcare Service. Hospital activity and analysis of hospital discharge forms in 2014 (Report)

41. Italian Ministry of Health (2013). Inpatient intervention tariffs. Italian Republic Official Gazette. Chapter n. 23; Supplement n. 8; 28 January 2013.

42. Fattore G. Proposta di linee guida per la valutazione economica degli interventi sanitari in Italia. PharmacoEconomics - Italian Research Articles 2009; 11: 83-93

43. Lucioni C, Ravasio R. Come valutare i risultati di uno studio farmacoeconomico? Pharmaco Economics Italian Res Articles 2004; 6: 121-30

44. Messori A, Santarlasci B, Trippoli S, ET AL. Controvalore economico del farmaco e beneficio clinico: stato dell'arte della metodologia e applicazione di un algoritmo farmacoeconomico. PharmacoEconomics Ital Res Artic 2003; 5: 53-67; https://doi.org/10.1007/ BF03320605

45. Martone N, Lucioni C, Mazzi S, et al. Valutazione di costo-efficacia dei nuovi farmaci oncologici immessi sul mercato italiano. Glob Reg Heal Technol Assess 2014; 1: 31-43

46. Jönsson B. Changing health environment: the challenge to demonstrate cost-effectiveness of new compounds. Pharmacoeconomics 2004; 22: 5-10; https://doi.org/10.2165/00019053200422004-00003

47. WHO, World Health Organization. Thresholds for the cost-effectiveness of interventions: alternative approaches. Available at: http:/www.who.int/bulletin/volumes/93/2/14-138206/ en (last accessed February 2018)

48. Mantovani LG, Furneri G, Bitonti R, et al. Cost-Effectiveness Analysis of Dimethyl Fumarate in the Treatment of Relapsing Remitting Multiple Sclerosis: An Italian Societal Perspective. Farmeconomia. Health economics and therapeutic pathways 2019; 20: 73-86; https://doi. org/10.7175/fe.v20i1.1437

49. Braune S, Grimm S, van Hövell P, et al. Comparative effectiveness of delayed-release dimethyl fumarate versus interferon, glatiramer acetate, teriflunomide, or fingolimod: results from the German NeuroTransData registry. J Neurol 2018; 265: 2980-92; https:// doi.org/10.1007/s00415-018-9083-5

50. Buron MD, Chalmer TA, Sellebjerg F, et al. Comparative effectiveness of teriflunomide and dimethyl fumarate: A nationwide cohort study. Neurology 2019; 92: e1811-20; https:// doi.org/10.1212/WNL.0000000000007314 


\section{SUPPLEMENTARY MATERIALS}

\begin{tabular}{|c|c|c|c|c|c|c|c|c|c|c|}
\hline \multirow{2}{*}{$\begin{array}{c}\text { From } \\
\text { EDSS level }\end{array}$} & \multicolumn{10}{|c|}{ RRMS to RRMS } \\
\hline & 0 & 1 & 2 & 3 & 4 & 5 & 6 & 7 & 8 & 9 \\
\hline 0 & 0.311 & 0.289 & 0.312 & 0.070 & 0.016 & 0.001 & 0.000 & 0.000 & 0.000 & 0.000 \\
\hline 1 & 0.178 & 0.231 & 0.419 & 0.127 & 0.039 & 0.004 & 0.001 & 0.000 & 0.000 & 0.000 \\
\hline 2 & 0.060 & 0.130 & 0.493 & 0.215 & 0.088 & 0.011 & 0.002 & 0.000 & 0.000 & 0.000 \\
\hline 3 & 0.019 & 0.055 & 0.299 & 0.322 & 0.241 & 0.044 & 0.013 & 0.003 & 0.004 & 0.000 \\
\hline 4 & 0.005 & 0.017 & 0.127 & 0.251 & 0.411 & 0.121 & 0.048 & 0.014 & 0.007 & 0.000 \\
\hline 5 & 0.001 & 0.004 & 0.033 & 0.096 & 0.252 & 0.295 & 0.211 & 0.085 & 0.023 & 0.000 \\
\hline 6 & 0.000 & 0.001 & 0.009 & 0.034 & 0.123 & 0.257 & 0.329 & 0.190 & 0.056 & 0.001 \\
\hline 7 & 0.000 & 0.000 & 0.003 & 0.013 & 0.057 & 0.169 & 0.309 & 0.257 & 0.189 & 0.004 \\
\hline 8 & 0.000 & 0.000 & 0.000 & 0.000 & 0.000 & 0.000 & 0.000 & 0.000 & 0.995 & 0.005 \\
\hline 9 & 0.000 & 0.000 & 0.000 & 0.000 & 0.000 & 0.000 & 0.000 & 0.000 & 0.000 & 1.000 \\
\hline \multirow{2}{*}{$\begin{array}{c}\text { From } \\
\text { EDSS level }\end{array}$} & & \multicolumn{9}{|c|}{ SPMS to SPMS } \\
\hline & & 1 & 2 & 3 & 4 & 5 & 6 & 7 & 8 & 9 \\
\hline 1 & & 0.769 & 0.154 & 0.077 & 0.000 & 0.000 & 0.000 & 0.000 & 0.000 & 0.000 \\
\hline 2 & & 0.000 & 0.636 & 0.271 & 0.062 & 0.023 & 0.008 & 0.000 & 0.000 & 0.000 \\
\hline 3 & & 0.000 & 0.000 & 0.629 & 0.253 & 0.077 & 0.033 & 0.003 & 0.005 & 0.000 \\
\hline 4 & & 0.000 & 0.000 & 0.000 & 0.485 & 0.350 & 0.139 & 0.007 & 0.018 & 0.000 \\
\hline 5 & & 0.000 & 0.000 & 0.000 & 0.000 & 0.633 & 0.317 & 0.022 & 0.026 & 0.002 \\
\hline 6 & & 0.000 & 0.000 & 0.000 & 0.000 & 0.000 & 0.763 & 0.190 & 0.045 & 0.002 \\
\hline 7 & & 0.000 & 0.000 & 0.000 & 0.000 & 0.000 & 0.000 & 0.805 & 0.189 & 0.006 \\
\hline 8 & & 0.000 & 0.000 & 0.000 & 0.000 & 0.000 & 0.000 & 0.000 & 0.926 & 0.074 \\
\hline 9 & & 0.000 & 0.000 & 0.000 & 0.000 & 0.000 & 0.000 & 0.000 & 0.000 & 1.000 \\
\hline
\end{tabular}

Supplementary Table I. Transition probabilities among disability progression levels, by MS form [23,24,27]

EDSS = expanded disability status scale; RRMS = relapsing remitting multiple sclerosis; SPMS = secondary progressive multiple sclerosis

\begin{tabular}{|c|c|c|c|c|c|c|c|c|c|}
\hline \multirow{2}{*}{ EDSS level } & \multicolumn{9}{|c|}{ RRMS to SPMS } \\
\hline & 1 & 2 & 3 & 4 & 5 & 6 & 7 & 8 & 9 \\
\hline Probability & 0.003 & 0.032 & 0.117 & 0.210 & 0.299 & 0.237 & 0.254 & 0.153 & 1.000 \\
\hline
\end{tabular}

Supplementary Table II. Transition probabilities from RRMS to SPMS form [27]

EDSS=expanded disability status scale; RRMS=relapsing remitting multiple sclerosis; SPMS=secondary progressive multiple sclerosis

\begin{tabular}{|c|c|c|c|c|c|c|c|c|}
\hline \multirow{2}{*}{ Adverse event } & \multicolumn{2}{|c|}{$\begin{array}{l}\text { Non-serious adverse } \\
\text { event (n/year) [32] }\end{array}$} & \multicolumn{2}{|c|}{$\begin{array}{c}\text { Serious adverse event } \\
\text { (n/year) [32] }\end{array}$} & \multicolumn{2}{|c|}{ Disutility value (n) } & \multicolumn{2}{|c|}{$\begin{array}{l}\text { Disutility duration } \\
\text { (days) }\end{array}$} \\
\hline & $\begin{array}{l}\text { Dimethyl } \\
\text { fumarate }\end{array}$ & Teriflunomide & $\begin{array}{l}\text { Dimethyl } \\
\text { fumarate }\end{array}$ & Teriflunomide & Non-serious & Serious & Non-serious & Serious \\
\hline Abdominal pain & 0.0514 & 0.0000 & 0.074 & 0.000 & 0.00 & 0.00 & 10.50 & 24.50 \\
\hline $\begin{array}{l}\text { Abdominal pain } \\
\text { upper }\end{array}$ & 0.0537 & 0.0000 & 0.000 & 0.000 & 0.00 & 0.00 & 10.50 & 24.50 \\
\hline ALT increased & 0.0313 & 0.1163 & 0.000 & 0.000 & 0.00 & 0.00 & 28.00 & 28.00 \\
\hline Arthralgia & 0.0463 & 0.0998 & 0.050 & 0.000 & 0.00 & 0.25 & 10.50 & 24.50 \\
\hline $\begin{array}{l}\text { Atrioventricular } \\
\text { conduction block }\end{array}$ & 0.0034 & 0.0000 & 0.000 & 0.000 & 0.29 & 0.29 & 1.00 & 1.00 \\
\hline Back pain & 0.0666 & 0.0890 & 0.027 & 0.000 & 0.25 & 0.50 & 10.50 & 24.50 \\
\hline Bradycardia & 0.0000 & 0.0000 & 0.000 & 0.000 & 0.00 & 0.00 & 14.00 & 14.00 \\
\hline Chest pain & 0.0061 & 0.0000 & 0.000 & 0.000 & 0.25 & 0.50 & 7.00 & 14.00 \\
\hline Cough & 0.0265 & 0.0000 & 0.000 & 0.000 & 0.00 & 0.00 & 7.00 & 14.00 \\
\hline Depression & 0.0371 & 0.0000 & 0.018 & 0.000 & 0.16 & 0.56 & 75.00 & 365.25 \\
\hline Diarrhea & 0.0762 & 0.1253 & 0.000 & 0.000 & 0.00 & 0.00 & 10.50 & 24.50 \\
\hline Fatigue & 0.0666 & 0.0990 & 0.000 & 0.000 & 0.00 & 0.00 & 182.63 & 182.63 \\
\hline
\end{tabular}




\begin{tabular}{|c|c|c|c|c|c|c|c|c|}
\hline \multirow{2}{*}{ Adverse event } & \multicolumn{2}{|c|}{$\begin{array}{c}\text { Non-serious adverse } \\
\text { event (n/year) [32] }\end{array}$} & \multicolumn{2}{|c|}{$\begin{array}{c}\text { Serious adverse event } \\
\text { (n/year) [32] }\end{array}$} & \multicolumn{2}{|c|}{ Disutility value $(n)$} & \multicolumn{2}{|c|}{$\begin{array}{l}\text { Disutility duration } \\
\text { (days) }\end{array}$} \\
\hline & $\begin{array}{l}\text { Dimethyl } \\
\text { fumarate }\end{array}$ & Teriflunomide & $\begin{array}{l}\text { Dimethyl } \\
\text { fumarate }\end{array}$ & Teriflunomide & Non-serious & Serious & Non-serious & Serious \\
\hline $\begin{array}{l}\text { Flu-like } \\
\text { symptoms }\end{array}$ & 0.0068 & 0.0295 & 0.000 & 0.000 & 0.31 & 0.31 & 26.00 & 52.00 \\
\hline Flushing & 0.1997 & 0.0000 & 0.006 & 0.000 & 0.00 & 0.00 & 10.50 & 24.50 \\
\hline Gastroenteritis & 0.0292 & 0.0000 & 0.143 & 0.000 & 0.07 & 0.07 & 8.75 & 8.75 \\
\hline Headache & 0.0956 & 0.1335 & 0.000 & 0.000 & 0.14 & 0.49 & 10.50 & 24.50 \\
\hline Influenza & 0.0377 & 0.0620 & 0.000 & 0.000 & 0.63 & 0.67 & 10.50 & 24.50 \\
\hline Leucopenia & 0.0048 & 0.0000 & 0.000 & 0.000 & 0.00 & 0.00 & 28.00 & 182.63 \\
\hline $\begin{array}{l}\text { Lower respiratory } \\
\text { tract infections }\end{array}$ & 0.0014 & 0.0000 & 0.000 & 0.000 & 0.05 & 0.05 & 11.70 & 11.70 \\
\hline Nausea & 0.0660 & 0.1021 & 0.025 & 0.000 & 0.00 & 0.00 & 10.50 & 24.50 \\
\hline Pain in extremity & 0.0406 & 0.0611 & 0.000 & 0.000 & 0.25 & 0.25 & 7.00 & 28.00 \\
\hline Pruritus & 0.0434 & 0.0141 & 0.000 & 0.000 & 0.00 & 0.00 & 10.50 & 24.50 \\
\hline Rash & 0.0406 & 0.0000 & 0.000 & 0.000 & 0.00 & 0.00 & 28.00 & 182.63 \\
\hline $\begin{array}{l}\text { Urinary tract } \\
\text { infection }\end{array}$ & 0.0764 & 0.0666 & 0.009 & 0.000 & 0.10 & 0.10 & 5.00 & 5.00 \\
\hline
\end{tabular}

Supplementary Table III. Annual incidence and disutilities related to adverse events

\begin{tabular}{|c|c|c|c|c|}
\hline \multirow{2}{*}{ Adverse event } & \multicolumn{2}{|c|}{ Unit cost $(€)$} & \multicolumn{2}{|c|}{ Source [38-41] } \\
\hline & Non-serious & Serious & Non-serious & Serious \\
\hline Abdominal pain & 20.66 & 20.66 & \multicolumn{2}{|c|}{ Code 89.7 tariff } \\
\hline $\begin{array}{l}\text { Abdominal pain } \\
\text { upper }\end{array}$ & 20.66 & 20.66 & & \\
\hline ALT increased & 11.24 & 31.90 & $\begin{array}{c}\text { Sum of the tariffs of the codes: } \\
90.10 .5 ; 90.09 .2 ; 90.04 .5 ; 90.23 .5 \\
90.25 .5\end{array}$ & $\begin{array}{l}\text { Sum of the tariffs of the codes: } 90.10 .5 \\
90.09 .2 ; 90.04 .5 ; 90.23 .5 ; 90.25 .5 ; 89.7\end{array}$ \\
\hline Arthralgia & 20.66 & 20.66 & \multicolumn{2}{|c|}{ Code 89.7 tariff } \\
\hline $\begin{array}{l}\text { Atrioventricular } \\
\text { conduction block }\end{array}$ & 192.49 & $1,943.13$ & $\begin{array}{l}\text { Average tariff of } \mathrm{DH} 138 \text { and } \\
\text { DH } 139\end{array}$ & $\begin{array}{c}\text { Average tariff of DRG } 138 \text { and DRG } 139 \\
+ \text { ER }\end{array}$ \\
\hline Back pain & 20.66 & 20.66 & \multicolumn{2}{|c|}{ Code 89.7 tariff } \\
\hline Bradycardia & 192.49 & $1,566.40$ & $\begin{array}{l}\text { Average tariff of } \mathrm{DH} 138 \text { and } \\
\qquad \mathrm{DH} 139\end{array}$ & Average tariff of DRG 138 and DRG 139 \\
\hline Chest pain & 20.66 & $1,399.00$ & Code 89.7 tariff & DRG 143 tariff \\
\hline Cough & 20.66 & 20.66 & \multicolumn{2}{|c|}{ Code 89.7 tariff } \\
\hline Depression & 87.74 & 858.00 & $\begin{array}{l}\text { Code } 89.7 \text { tariff }+6 \text { months } \\
\text { of treatment with sertraline }\end{array}$ & DRG 426 tariff \\
\hline Diarrhea & 20.66 & $1,408.27$ & Code 89.7 tariff & Average tariff of DRG 182 and DRG 183 \\
\hline Fatigue & 0.00 & 0.00 & & - \\
\hline Flu-like symptoms & 0.00 & 20.66 & - & Code 89.7 tariff \\
\hline Flushing & 20.66 & 20.66 & \multicolumn{2}{|c|}{ Code 89.7 tariff } \\
\hline Gastroenteritis & 183.65 & $1,408.27$ & $\begin{array}{l}\text { Average tariff of } \mathrm{DH} 182 \text { and } \\
\mathrm{DH} 183\end{array}$ & Average tariff of DRG 182 and DRG 183 \\
\hline Headache & 0.00 & 20.66 & - & Code 89.7 tariff \\
\hline Influenza & 15.48 & 214.01 & GP visit & Average tariff of $\mathrm{DH} 79$ and $\mathrm{DH} 80$ \\
\hline Leucopenia & 3.91 & 28.48 & Code 90.70 .4 tariff & Sum code 90.70 .4 and 89.7 tariffs \\
\hline $\begin{array}{l}\text { Lower respiratory } \\
\text { tract infections }\end{array}$ & 15.48 & $5,327.80$ & GP visit & Average tariff of DRG 79 and DRG 80 \\
\hline Nausea & 0.00 & 20.66 & - & Code 89.7 tariff \\
\hline Pain in extremity & 20.66 & 30.99 & Code 89.7 tariff & Sum code 93.08 .1 and 89.7 tariffs \\
\hline Pruritus & 0.00 & 20.66 & - & Code 89.7 tariff \\
\hline Rash & 20.66 & 218.00 & Code 89.7 tariff & DH 447 tariff \\
\hline Urinary tract infection & 20.66 & $2,296.56$ & Code 89.7 tariff & Average tariff of DRG 320 and DRG 321 \\
\hline
\end{tabular}

Supplementary Table IV. Unit costs of adverse events

$\mathrm{DH}$ = day-hospital; DRG = diagnosis-related group; $\mathrm{ER}=$ emergency room admission; GP = general practitioner 


\begin{tabular}{|c|c|c|c|}
\hline Item & Dimethyl fumarate (A) & Teriflunomide (B) & Difference (A-B) \\
\hline \multicolumn{4}{|l|}{ Outcome } \\
\hline LYs & 19.634 & 19.547 & 0.087 \\
\hline QALYS & 6.526 & 5.953 & 0.573 \\
\hline \multicolumn{4}{|l|}{ Costs $(€)$} \\
\hline Treatment costs ${ }^{1}$ & 94,637 (27.1\%) & 72,608 (21.5\%) & 22,030 \\
\hline Adverse events & 261 (0.07\%) & 87 (0.03\%) & 173 \\
\hline Relapse $^{2}$ & $25,301(7.3 \%)$ & $28,235(8.4 \%)$ & $-2,934$ \\
\hline EDSS $^{2}$ & 228,495 (65.5\%) & $236,472(70.1 \%)$ & $-7,977$ \\
\hline Inpatient care & $136,387(39.1 \%)$ & $142,154(42.1 \%)$ & $-5,767$ \\
\hline Day admission & 34,508 (9.9\%) & $35,290(10.5 \%)$ & -782 \\
\hline Consultations & 23,957 (6.9\%) & 24,795 (7.3\%) & -838 \\
\hline Tests & $12,826(3.7 \%)$ & $12,772(3.8 \%)$ & 54 \\
\hline Medication & 20,817 (6.0\%) & $21,461(6.4 \%)$ & -644 \\
\hline Total costs & $348,694(100.00 \%)$ & $337,402(100.00 \%)$ & $-11,292$ \\
\hline ICER (€/QALY gained) & & 19,691 & \\
\hline
\end{tabular}

Supplementary Table V. Results of the incremental cost-effectiveness analysis (alternative scenario \#1: NHS perspective and lifetime horizon)

${ }^{1}$ Including monitoring costs

${ }^{2}$ Including only direct costs

EDSS = expanded disability status scale; ICER = incremental cost-effectiveness ratio; LYs = life-years; QALYs = quality-adjusted life years 